\title{
Effect of Fetal Serum and Follicular Liquor Supplementation on the In Vitro Production of Bovine Embryos
}

\author{
${ }^{1}$ Clara Larocca, ${ }^{1}$ Yael Filipiak, ${ }^{2}$ William Perez and ${ }^{2}$ Juan Calvo \\ ${ }^{1}$ Department of Animal Reproduction, Faculty of Veterinary, \\ University of the Republic, Lasplaces 1620, Montevideo 11600, Uruguay \\ ${ }^{2}$ Department of Morphology and Development, Faculty Veterinary, \\ University of the Republic, Lasplaces 1620, Montevideo 11600, Uruguay
}

Received 2012-06-13, Revised 2012-08-08; Accepted 2012-08-09

\begin{abstract}
To optimize In Vitro Fertilization (IVF) results in bovines by lowering costs, comparing the efficiency of Fetal Calf Serum (FCS) (high cost) with respect to bovine Follicular Fluid (bFF) (low cost) and by quantifying embryo production. Cumulus-Oocyte-Complexes (COC) obtained from a slaughter house, transported at $37^{\circ} \mathrm{C}$ in saline solution, were classified according to their quality in A, B, C and D. A and B oocytes were washed with modified Phosphate-Buffered Saline (m-PBS) and three groups were randomly formed (GC; G1; G2) cultured in drops of the respective media (10 COC/drop of $100 \mu \mathrm{L})$, covered with mineral oil and placed in an incubator $\left(38,5^{\circ} \mathrm{C}, 5 \% \mathrm{CO}_{2}\right.$ y $95 \%$ humidity). Maturation was done in Tissue Culture Medium (TCM-199) and antibiotics, for $22 \mathrm{~h}$ and developed in CR1aa medium and antibiotics. The Control Group (CG) was supplemented during both maturation and development stages with 5\% FCS and $10 \% \mathrm{bFF}$; G1 with 5\% FCS during maturation and development and G2 with $10 \%$ bFF during maturation and development. We obtained bFF from follicles larger than $15 \mathrm{~mm}$, it was centrifuged (800G) inactivating it. At fertilization Bracket and Oliphant (BO) medium was used. Zygotes were evaluated every $48 \mathrm{~h}$ for 8 days since insemination, counting the Division Rate (DR) and the Embryo Development (ED) of compacted morulae. $\mathrm{X}^{2}$ Test was applied. For RD, G2 differs from G1 and CG ( $\left.<<0.05\right), \mathrm{CG}$ and $\mathrm{G} 1$ do not differ significantly $(p>0.05)$. During development no significant differences were found between groups $(p>0.05)$. Results show that when using FCS, bFF or a combination of both, development results are similar. It is assumed that it is possible to substitute FCS with bFF.
\end{abstract}

Keywords: In Vitro Fertilization, Oocytes, Culture Media, Protein Supplementation, In Vitro Maturation, In Vitro Development

\section{INTRODUCTION}

In vitro production of bovine embryos is a biotechnology that makes it possible to obtain a higher number of calves per year from a single female for variable production objectives, in particular genetic advances, however, the rate of viable embryos obtained for embryo transfer by this method is still low (López et al., 2005). The first calves obtained by IVF were reported in 1987 (First and Parrish, 1987). In 1992, the first two calves from Latin America were born at the Laboratorio de Biotecnología de la Facultad de Veterinaria, Uruguay (reported by the press). The increment in the use of the Ovum Pick Up (OPU) technique, mainly in cows with genetic value, calls for a new need to increase the efficiency in the production of embryos by IVF, lowering at the same time its costs. One of the problems is the supplementation of the culture media with FCS because of its high cost (Triana et al., 1997). bFF is easily available and can be obtained at a

Corresponding Author: Clara Larocca, Department of Animal Reproduction, Faculty of Veterinary, University of the Republic, Lasplaces 1620, Montevideo 11600, Urugua 
minimal cost, by preovulatory follicular aspiration. Research that contributes to a higher efficiency and a lower cost of IVF has a direct influence in production.

Some of the benefits of using serum are: it contributes with proteins; protection of the embryos in culture medium from toxic substances (e.g., heavy metals); provides growth factors; lowers the surface tension of the medium, preventing the embryos from attaching to instruments (culture plaques, pipettes, tubes) (Mucci et al., 2006). Research has shown that the addition of bFF to maturation and in vitrodevelopment media for bovine embryos has a favorable effect (Larocca et al., 1993; 1997; Romero-Arredondo and Seidel, 1994), since it also has hormones needed for maturation. There are also studies done that compare the effect of $0.6 \%$ bovine Serum Albumin (bSA), $10 \%$ Estrous Cow Serum (ECS) and 10\% FCS as protein sources for the production of embryos (López et al., 2005). High concentrations of FSH (Suchanek et al., 1988), hCG (Ellsworth et al., 1984) and LH (Cha et al., 1986), associated with estrogens present in bFF have been reported to promote ovocyte maturation and are related to ovocytes that have a high probability of being fertilized (Revelli et al., 2009). From a physiologic standpoint, follicular liquor provides an important microclimate por ovocyte development, being produced from plasma transudate and the secretion from granulosa and follicular theca cells (Revelli et al., 2009).

The aim of this study is to compare the performance of FCS with that of bFF on the embryos produced, with the objective of evaluating its efficiency in the production of embryos and if it is possible to substitute FCS with bFF in IVF. With this project we try to determine if bFF behaves equally or better than FCS under the same conditions within the IVF culture of bovine ovocytes, so as to determine if it is possible to substitute FCS.

\section{MATERIALS AND METHODS}

Ovocytes were obtained from bovine ovaries from an abattoir less than three hours after slaughter and transported in isotonic saline solution at $37^{\circ} \mathrm{C}$. Follicles measuring between 2 and $8 \mathrm{~mm}$ in diameter were aspirated using a $5 \mathrm{ml}$ syringe and an $18 \mathrm{G}$ needle. Aspiration medium was m-PBS, with 5\% FCS and antibiotics. COC were classified under stereoscopic microscope $40 \times$ as class A when having more than 3 layers of cumulus cells and a homogeneous cytoplasm; class B, with less than three layers of cells or with cumulus cells that do not completely cover the ovocyte and an irregular cytoplasm; C, naked and D, degenerated (IETS standards). Those of A and B quality were washed
2 times in m-PBS. Three groups were formed, randomly chosen with the same number of COC. CG: maturation culture was done in TCM-199 supplemented with FCS $5 \%$, bFF $10 \%$ and antibiotics, in $100 \mu \mathrm{L}$ drops, 10 ovocytes per drop covered with mineral oil, in an incubator $\left(38^{\circ} \mathrm{C}, 5 \% \mathrm{CO}_{2}\right.$ in air and $95 \%$ relative humidity) for $22 \mathrm{~h}$. For development CR1aa medium were used $+5 \%$ FCS $+10 \%$ bFF + antibiotics, in incubator, for 8 days. Group 1 (G1): cultured for maturation in TCM-199 supplemented with FCS 5\% and antibiotics. In the development medium CR 1 aa $+5 \%$ FCS and antibiotics, with the same method as described for CG. Group 2 (G2): Cultured for maturation in TCM199 supplemented with bFF $10 \%$ and antibiotics. For development $\mathrm{Cr} 1 \mathrm{aa}+\mathrm{bFF} 10 \%$ and antibiotics was used.

bFF was obtained from follicles measuring more than $15 \mathrm{~mm}$, centrifuged twice at $800 \mathrm{~g}$, supernatant inactivated at $56^{\circ} \mathrm{C}$ (Calvo et al., 2004), aliquoted and conserved at $-20^{\circ} \mathrm{C}$.

After maturation all $\mathrm{COC}$ were inseminated in vitro. A tested semen straw, was additioned with BO semen wash with caffeine and heparin. It was centrifuged at $450 \mathrm{~g}$ for $5 \mathrm{~min}$ and the supernatant discarded. The semen pellet was adjusted at $1-2$ million sperm $/ \mathrm{mL}$ with diluting BO solution, after the total concentration was calculated using a Neubauer chamber. Drops of $100 \mu \mathrm{L}$ were formed with the semen, covered in mineral oil, COC from each group were placed in the drops and then incubated at $38^{\circ} \mathrm{C}$, with $5 \% \mathrm{CO}_{2}$ in the air and $95 \%$ relative humidity for 5-6 h. After insemination gametes were washed in TCM-199 with Hepes and then were denuded with a sharpened Pasteur pipette. Fertilized COC were cultured for their development as described for each group. Cleavage was studied at $48 \mathrm{~h}$ with an inverted microscope at 200×. Divided embryos were counted and compared to the number of COC fertilized for each group. Embryo development was assessed every $48 \mathrm{~h}$ until day 8 from insemination, counting compacted morulas and/or blastocysts (transfer stages). All the experiments were done using the same serum lot and semen from the same bull.

12 replics were done and results compared using $\chi^{2}$ test (Siegel and Castellan, 1988).

\section{RESULTS}

Forty eight hours after IVF in the CG, from a total of 181 COC, 79 divided (DR: 43,6 p.100) and 29 developed into compacted morulae (ED/DR: 36,7 p.100); in G1, form 183 COC, 70 divided (DR: 38,3 p. 100) and 37 developed into compacted morulae (CM) (ED/DR: 52,9 p. 
100); in G2 from 173 COC, 97 divided (DR: 56 p. 100) and 40 developed a CM (ED/DR: 41,2 p. 100).

For DR, G2 differs significantly from G1 and CG $(\mathrm{p}<0.05)$, while $\mathrm{CG}$ and $\mathrm{G} 1$ do not show significant changes $(p>0.05)$. For the development phase statistics showed no differences between the groups $(p>0.05)$.

During cleavage, G2, supplemented only with bFF, performed better, while during development all three groups behaved in a similar way. The results show that either using FCS, bFF or a combination of both; similar results are obtained for development, suggesting that FCS could be replaced with bFF in the bovine IVF culture.

\section{DISCUSSION}

Serum is considered a variable and undefined component (Gardner and Lane, 1998), which creates variations in media used and interferes with the repeatability of the results obtained. Most researchers use hormones and FCS in the media (Pinyopummintr and Bavister, 1994). In this sense there are differences in the rate of production between the different trials published where serum is used as a proteic supplement (Hammond et al., 2000).

The effect produced by the additions of bFF to the maturation medium has been studied and they show positive results (Romero-Arredondo and Seidel, 1994; Sirard et al., 1995), coinciding with the results of this study. Calvo et al. (2004) by adding $10 \%$ bFF to a medium containing FCS obtained better results with respect to the group without bFF. The present study shows a significant difference in the cleavage rate when $\mathrm{bFF}$ is used alone during maturation and development, not being significant in the embryos obtained, these results are similar to the ones aforementioned, taking into account a better performance when only bFF was used during maturation and development.

Choi et al. (1998), used bFF as an additive to the culture medium without obtaining any benefit on the development rate. The author concludes that there is a need for futher research, using bFF derived from preovulatory follicles.

\section{CONCLUSION}

The present work, which deepens in the study of the effects of bFF on IVF found that given the results obtained it is possible to substitute FCS with bFF in the IVF cultures.

\section{REFERENCES}

Calvo, J., G. Roses, C. Larocca, M. Viqueira and I. Lago, 2004. Diferentes fuentes de líquido folicular en el desarrollo "in vitro" de embriones bovinos. Arch. Zootec., 53: 329-332.

Cha, K.Y., R.B. Barnes, R.P. Marrs and R.A. Lobo, 1986. Correlation of the bioactivity of luteinizing hormone in follicular fluid with oocyte maturity in the spontaneous cycle. Fertil. Steril., 45: 338341.

Choi, Y.H., M. Takagi, H. Kamishita, M.P.B. Wijayagunawardane and T.J. Acosta et al., 1998. Developmental capacity of bovine oocytes matured in two kinds of follicular fluid and fertilized in vitro. Anim. Reprod. Sci., 50: 27-33.

Ellsworth, L.R., J.P. Balmaceda, R.S. Schenken, A.Y. Silverman and T.J. Prihoda et al., 1984. Human chorionic gonadotropin and steroid concentrations in human follicular fluid in relation to follicle size and oocyte maturity in stimulated ovarian cycles. Acta Eur. Fertil., 15: 343-346. PMID: 6084941

First, N.L. and J. Parrish, 1987. In-vitro fertilization of ruminants. J. Reprod. Fert. 34: 151-165. PMID: 3305915

Gardner, D.K. and M. Lane, 1998. Culture of viable human blastocysts in defined sequential serum-free media. Hum. Reprod., 13: 148-159. DOI: 10.1093/humrep/13.suppl 3.148

Hammond, D.S., S. Wang and G.R. Holyoak, 2000. Effects of ammonia during different stages of culture on development of in vitro produced bovine embryos. Theriogenology, 52: 23-30.

Larocca, C., S. Kmaid and J. Calvo, 1993. Effect of folicular fluid and oestrus cow serum on maturation, fertilization and development of the bovine ocyte in vitro. Theriogenology, 39: 253253.

Larocca, C., S. Kmaid, I. Lago, G. Roses and D. Fila et al., 1997. Influence of follicular fluid from different sources on in vitrodevelopment of bovine embryos produced in vitro. Theriogenology, 47: 292-292. DOI: 10.1016/S0093-691X(97)82419-3

López, A., A. Tarazona and M. Olivera-Angel, 2005. Efecto del cocultivo sobre el desarrollo temprano de embriones bovinos producidos in vitro. Rev. Col. Cenc. Pec., 18: 4-4. 
Mucci, N., J.F. Aller, G.G. Kaiser, F. Hozbor and R.H. Alberio, 2006. Produccion in vitro de embriones bovinos: Suplementacion de los medios de cultivo con suero. Arch. Med. Vet., 38: 97-104.

Pinyopummintr, T. and B.D. Bavister, 1994. Development of bovine embryos in a cell-free culture medium: Effects of type of serum, timing of its inclusion and heat inactivation. Theriogenology, 41: 1241-1249. PMID: 16727477

Revelli, A., L. Delle-Piane, S. Casano, E. Molinari and M. Massobrio et al., 2009. Follicular fluid content and oocyte quality: From single biochemical markers to metabolomics. Reproductive Biol. Endocrinol., 7: 40-40. DOI: $10.1186 / 1477-7827-7-40$

Romero-Arredondo, A. and J.E. Siedel Jr., 1994. Effects of bovine folicular fluid on the maturation of bovin oocytes. Theriogenology, 41: 383-394. DOI: 10.1016/0093-691X(94)90074-S

Siegel, S. and N.J. Castellan, 1988. Nonparametric Statistics for the Behavioral Sciences. 2ns Edn., McGraw-Hill, New York, ISBN-10: 0070573573, pp: 399.
Sirard, M.A., F. Roy, B. Patrick, P. Merimillod and L.A. Guilbault, 1995. Origin of the follicular fluid added to the media during bovine IVM influences embryonic development. Theriogenology, 44: 85-94. DOI: 10.1016/0093-691X(95)00150-7

Suchanek, E., V. Simunic, E. Macas, B. Kopjar and V. Grizelj, 1988. Prostaglandin F2 alpha, progesterone and estradiol concentrations in human follicular fluid and their relation to success of in vitro fertilization. Eur. J. Obstet. Gynecol. Reprod. Biol., 28: 331-339. PMID: 3139478

Triana, I.D., M.E. Sondon Fernandez, P. Bahr Valcarcel and L.A Escalona, 1997. Estudio de la influencia del suero equino en el crecimiento de mielomas murinos. Facultad de Ciencias Medicas de Holguin. Correo Cientifico Medico de Hoguin. 